\title{
A novel anti-proliferative pentapeptide (ILYMP) isolated from Cyclina sinensis protein hydrolysate induces apoptosis of DU-145 prostate cancer cells
}

\author{
FANGMIAO YU ${ }^{1,2}$, YARU ZHANG ${ }^{1}$, LEI YE $^{1}$, YUNPING TANG $^{1}$, \\ GUOFANG DING ${ }^{1,2}$, XIAOJUN ZHANG ${ }^{2}$ and ZUISU YANG ${ }^{1}$
}

\begin{abstract}
${ }^{1}$ School of Food and Pharmacy, Zhejiang Provincial Engineering Technology Research Center of Marine Biomedical Products, Zhejiang Ocean University, Zhoushan, Zhejiang 316022; ${ }^{2}$ Aquatic Processing Department, Zhejiang Marine Fisheries Research Institution, Zhoushan, Zhejiang 316021, P.R. China
\end{abstract}

Received October 24, 2017; Accepted April 16, 2018

DOI: $10.3892 / \mathrm{mmr} .2018 .9019$

\begin{abstract}
Prostate cancer is the main causes of cancer associated mortality in men worldwide, cancer patients often suffer serious side effects when treated with chemotherapy or radiotherapy, therefore novel drugs are in high demand to treat prostate cancer. In the present study, a pentapeptide (Ile-Leu-Tyr-Met-Pro; ILYMP) with a molecular weight of 635.71 Da was isolated from the protein hydrolysate of Cyclina sinensis via ultrafiltration and chromatographic methods, and subsequently named Cyclina sinensis pentapeptide (CSP). The activity of CSP was first investigated in prostate cancer (PCa) DU-145 cells. CSP was demonstrated to significantly inhibit DU-145 cell proliferation at a half-maximal inhibitory concentration of $11.25 \mathrm{mM}$ at a $72 \mathrm{~h}$ time interval. In addition, the results of acridine orange/ethidium bromide double staining, scanning electron microscopy and flow cytometry analyses suggested that CSP inhibited DU-145 cell proliferation via the induction of apoptosis. Following treatment with CSP, Bcl-2-associated X (Bax), cleaved caspase-3 and cleaved caspase- 9 protein expression levels were enhanced in DU-145 cells; whereas B-cell lymphoma 2 expression was suppressed in DU-145 cells. In conclusion, to the best of the authors' knowledge, this is the first study to investigate the effects of an anti-proliferative peptide derived from Cyclina sinensis on DU-145 cells, and the results suggested that CSP may represent a therapeutic nutraceutical agent for the treatment of patients with PCa.
\end{abstract}

Correspondence to: Professor Zuisu Yang, School of Food and Pharmacy, Zhejiang Provincial Engineering Technology Research Center of Marine Biomedical Products, Zhejiang Ocean University, 1 Haida South Road, Lincheng, Changzhi Island, Zhoushan, Zhejiang 316022, P.R. China

E-mail: abc1967@126.com

Key words: Cyclina sinensis, prostate cancer, protein hydrolysate, peptide, anticancer activity, apoptosis

\section{Introduction}

Prostate cancer $(\mathrm{PCa})$ is one of the most prevalent malignancies in men in the USA and worldwide, and is the second leading cause of cancer associated mortality in men $(1,2)$. Each year, more than 913,000 novel cases are diagnosed worldwide, resulting in the mortalities of $>261,000$ patients (3). In addition, the incidence and mortality rate of $\mathrm{PCa}$ in China continues to rapidly increase, particularly in patients suffering from obesity or diabetes $(4,5)$. Androgen deprivation therapy has been previously demonstrated to be effective in $\sim 90 \%$ of patients with PCa. However, androgen deprivation therapy may develop into androgen-independent PCa and eventually into lethal, castration-resistant PCa (6). Researchers have developed second generations of hormone therapy, such as abiraterone and enzalutamide for the treatment of PCa $(7,8)$. Despite such therapies improving overall survival, the majority of patients with PCa develop resistance following initial treatment, and so further investigation is required to develop novel therapeutic treatment strategies with a low toxicity.

Biofunctional peptides (2-20 amino acids) are protein fragments that may exhibit numerous physiological effects, such as anticancer $(9,10)$, anti-thrombosis $(11)$, antioxidant $(12,13)$, anti-fatigue $(14,15)$ and antimicrobial $(16,17)$. Recently, numerous antitumor peptides have been isolated from marine derived protein hydrolysates to induce PCa cell apoptosis (18-20). Huang et al (18) demonstrated that a tripeptide (Gln-Pro-Lys; QPK) isolated from sepia ink inhibits the proliferation of numerous human PCa lines (DU-145, PC-3 and LNCaP); whereas Song et al (19) revealed that a hexapeptide (Tyr-Ala-Leu-Arg-Ala-His; YALRAH), obtained from the heated products of protein hydrolysates isolated from Setipinna taty, inhibits PC-3 cell proliferation. Furthermore, Kim et al (20) demonstrated that a decapeptide (Ala-Val-Leu-V al-Asp-Lys-Gln-Cys-Pro-Asp; AVLVDKQCPD), isolated from the protein hydrolysates of Ruditapes philippinarum, inhibits the proliferation of PCa cells. Notably, numerous biofunctional peptides have been purified from fish sources, whereas only a number of studies have investigated proteins obtained from crustacean and mollusk sources. Cyclina sinensis, a bivalve mollusk belonging to the Veneridae family, has been 
used in traditional Chinese medicine for the treatment of inflammation, asthma and dental ulcers $(21,22)$. Furthermore, it has been revealed that Cyclina sinensis has a high quantity of protein, polysaccharides and lipids, which may attribute to its therapeutic effects, such as anticancer, antioxidant and hepatoprotective activities (21-23).

Jiang et al $(22,23)$ reported that the polysaccharide fraction of Cyclina sinensis (CSPS) exhibits significant inhibitory effects against human gastric cancer BGC-823 cells in vivo. In our previous study (24), the anti-proliferative potential of protein hydrolysates isolated from Cyclina sinensis was determined; however, the active component in the protein hydrolysates was not investigated further. Therefore, the present study aimed to isolate the pentapeptide (Ile-Leu-Tyr-Met-Pro; ILYMP) of interest from Cyclina sinensis protein hydrolyastes via ultrafiltration as well as chromatographic methods, and was subsequently named CSP. The effect of CSP on the PCa cell line DU-145 was investigated using methylthiazolyldiphenyl-tetrazolium bromide (MTT) assays, acridine orange/ethidium bromide double staining (AO/EB), scanning electron microscopy and flow cytometry. Furthermore, western blotting was performed, and the results demonstrated that the Bcl-2-associated X (Bax), cleaved caspase- 3 and cleaved caspase- 9 proteins were activated in CSP-treated DU-145 cells; whereas B-cell lymphoma-2 (Bcl-2) was suppressed in CSP-treated DU-145 cells. These results suggest that CSP can inhibit the proliferation of human $\mathrm{PCa}$ cells and may represent a therapeutic nutraceutical agent for the treatment and prevention of PCa.

\section{Materials and methods}

Materials. Cyclina sinensis were purchased from a local fish market in Zhoushan, China. Trypsin and neutral protease were purchased from YTHX Biotechnology Co., Ltd. (Beijing, China). MTT and Annexin V-FITC apoptosis detection kits were purchased from Sigma-Aldrich; Merck KGaA (Darmstadt, Germany). The DU-145 PCa cell lines and NIH-3T3 cell lines were purchased from the Shanghai Institute of Biochemistry and Cell Biology (Shanghai, China). Antibodies against $\beta$-actin (cat. no. AA132), Bax (cat. no. AB026), Bcl-2 (cat. no. AB112), caspase-3 (cat. no. AC030) and caspase-9 (cat. no. AC062) were purchased from Beyotime Institute of Biotechnology (Shanghai, China). Horseradish peroxidase-conjugated goat-anti-rabbit secondary antibodies (cat. no. A0208) were purchased from Beyotime Institute of Biotechnology. All other reagents used were of analytical grade.

Fractionation of protein hydrolysates by ultrafiltration. Cyclina sinensis were hydrolyzed using neutral protease under conditions: $1,200 \mathrm{U} / \mathrm{g}$, solid-liquid ratio $1: 4,(\mathrm{pH} 7.0)$ at $45^{\circ} \mathrm{C}$ for $6 \mathrm{~h}$. The protein hydrolysates were then fractionated using ultrafiltration (Amicon 8400; EMD Millipore, Billerica, MA, USA) with 3,5 and $8 \mathrm{kDa}$ molecular weight cut-off membranes at $0.30 \mathrm{MPa}, 20^{\circ} \mathrm{C}$. The fractions were then collected as follows: $>8,8-5,5-3$, and $<3 \mathrm{kDa}$. Fractions were then lyophilized at $-60^{\circ} \mathrm{C}$ to further investigate whether Cyclina sinensis exhibits an antitumor effect on DU-145 cells.

Gel filtration chromatography. The elution with the highest antitumor activity following ultrafiltration was dissolved in
$0.1 \mathrm{M}$ Tris- $\mathrm{HCl}(0.05 \mathrm{~g} / \mathrm{ml}, \mathrm{pH} 7.0), 500 \mu \mathrm{l}$ sample was added to a Superose 12 10/300 GL (GE Healthcare, Chicago, IL, USA; 10x300 mm) pre-equilibrated with Tris- $\mathrm{HCl}(0.1 \mathrm{M}, \mathrm{pH} 7.0)$ and then eluted at a flow rate of $1 \mathrm{ml} / \mathrm{min}$ using an AKTA purifier 100 (GE Healthcare) at room temperature. Fractions were isolated and detected at $280 \mathrm{~nm}$, and the elution peaks were then isolated and lyophilized at $-60^{\circ} \mathrm{C}$ to investigate antitumor activity analysis.

High performance liquid chromatography (HPLC). The elution with the highest antitumor activity was further separated using reverse phase (RP)-HPLC (Agilent 1260; Agilent Technologies, Inc., Santa Clara, CA, USA) on a Agilent Zorbax SB-C18 $(4.6 \times 250 \mathrm{~mm} ; 5 \mu \mathrm{m})$ column with a linear gradient of acetonitrile $(0-7 \%)$ containing $0.06 \%$ trifluoroacetic acid at a flow rate of $1.0 \mathrm{ml} / \mathrm{min}$. The purification was repeated $>20$ times at the same elution conditions and the final purified peptide (CSP) was collected and subsequently lyophilized at $-60^{\circ} \mathrm{C}$ to determine its amino acid sequence as well as its antitumor activity against DU-145 cells.

Determination of amino acid sequence and molecular mass of CSP. CSP was dissolved in $15 \mu 137 \% \mathrm{CH}_{3} \mathrm{CN}$ (v/v) solution and applied to TFA-treated glass fiber filters (Shimadzu Corporation, Kyoto, Japan) and then sequenced at the N-terminus using a PPSQ-31A protein sequencer (Shimadzu Corporation). A mass spectrometer (Waters ZQ 2000; Waters $\mathrm{GmbH}$, Eschborn, Germany) combined with an electrospray ionization source was used to determine the molecular weight of the final purified peptide. Ionization was carried out in positive ion mode with a capillary voltage of $3.5 \mathrm{kV}$, a nebulizer gas $\left(\mathrm{N}_{2}\right)$ temperature of $250^{\circ} \mathrm{C}$ and flow rate of $1.51 / \mathrm{min}$.

Anti-proliferative activity against DU-145 cells. The effects of CSP on cell proliferation were determined using the MTT colorimetric assay according to the protocol detailed by Tang et al (25), with a number of modifications. Briefly, DU-145 cells were seeded in a 96 -well plate $\left(1 \times 10^{4}\right.$ cells/well) and incubated at $37^{\circ} \mathrm{C}$ overnight. Cells were then treated with different concentrations of CSP $(0,3.0,6.0,12.0,18.0$ and $22.5 \mathrm{mM})$ for 24,48 and $72 \mathrm{~h}$ time intervals at $37^{\circ} \mathrm{C}$. Following this, PBS $(200 \mu \mathrm{l})$ with $10 \%$ MTT was added to each well at room temperature. The medium was then removed, DMSO $(150 \mu \mathrm{l})$ was added and the plates were then incubated at $37^{\circ} \mathrm{C}$ for a further $4 \mathrm{~h}$. The plates was transferred into a TYZD-I oscillator (Beijing BILON Co., Ltd., Beijing, China) and incubated for $15 \mathrm{~min}$ at room temperature. The cell proliferation inhibition rate $(\%)$ was calculated using the following equation: Inhibition percentage $(\%)=\left[\left(\mathrm{OD}_{\text {control }}-\mathrm{OD}_{\text {treated }}\right) /\left(\mathrm{OD}_{\text {control }}-\mathrm{OD}_{\text {blank }}\right)\right] \times 100 \%$

Acridine orangelethidium bromide $(A O / E B)$ staining. Cell morphology was investigated using $\mathrm{AO} / \mathrm{EB}$ double staining as described by Tang et al (25). To accurately distinguish cells in different stages of apoptosis, DU-145 cells in exponential phase were digested using $0.25 \%$ trypsin, suspended at a final concentration of $1 \times 10^{5}$ cells/well in a 6-well flat-bottomed plate and then cultured at $37^{\circ} \mathrm{C}$ in a $5 \% \mathrm{CO}_{2}$ incubator. Cells were then treated with $0,3.0,12.0$ and $18.0 \mathrm{mM}$ CSP for a further $24 \mathrm{~h}$. Finally, cells were stained using the AO/EB dye mixture $(100 \mu \mathrm{g} / \mathrm{ml})$ and the morphology of apoptotic cells was then 

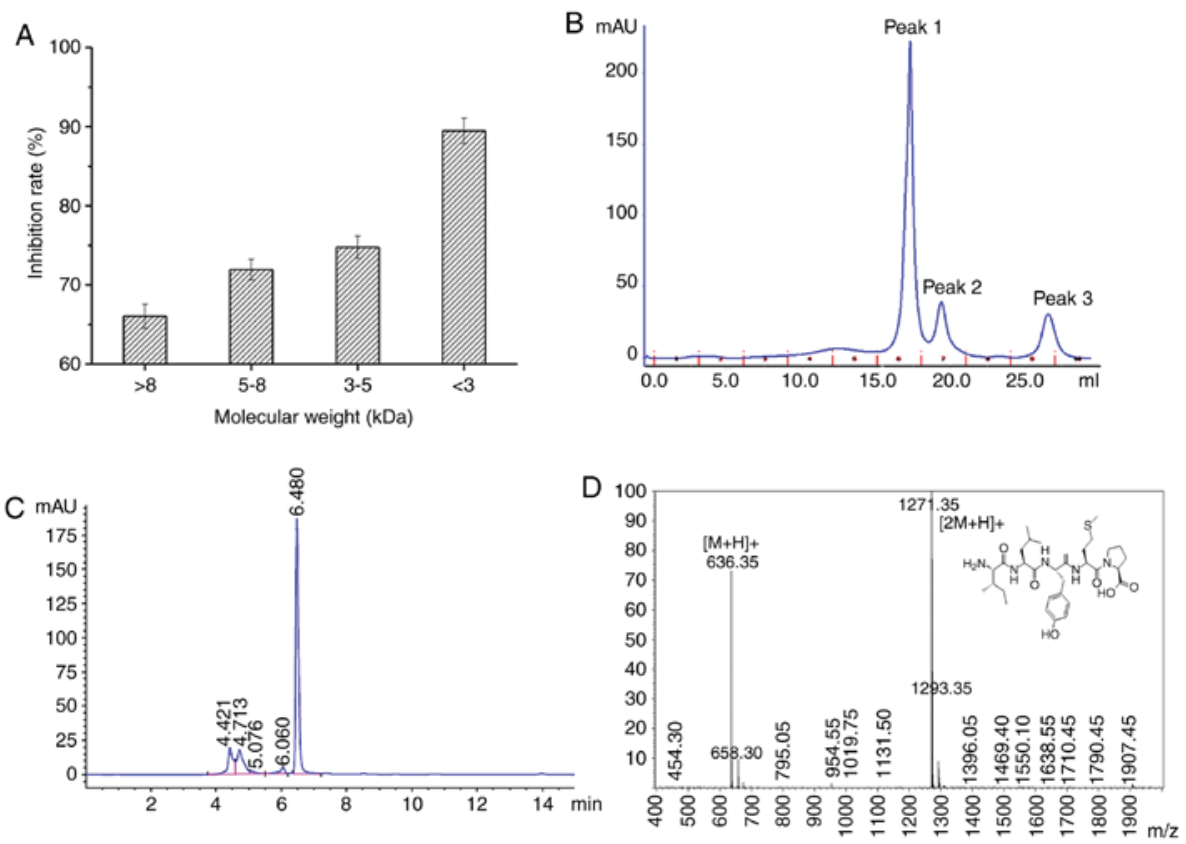

Figure 1. Purification and identification of activity peptide from protein hydrolysates isolated from Cyclina sinensis. (A) Cyclina sinensis were hydrolyzed using neutral protease, and protein hydrolysates $(>8,8-5,5-3$ and $<3 \mathrm{kDa}$ ) were fractionated via ultrafiltration. Following this, protein hydrolysates were lyophilized to determine the anti-proliferative ability of CSP towards DU-145 cells. (B) The elution (peak 1) exhibiting the greatest inhibitory effect following ultrafiltration was then isolated via gel filtration chromatography. (C) The elution with highest antitumor activity (peak 1) was further separated using reverse phase high performance liquid chromatography on a Zorbax SB-C18 column with a linear gradient of acetonitrile (0-7\%) containing $0.06 \%$ trifluoroacetic acid at a flow rate of $1.0 \mathrm{ml} / \mathrm{min}$. (D) A mass spectrometer combined with an electrospray ionization source was used to determine the molecular weight of the CSP (635.71 Da).

immediately investigated using a fluorescent microscope (Leica DM 3000; Leica Microsystems GmbH, Wetzlar, Germany).

Scanning electron microscope. DU-145 cells were seeded in a $25 \mathrm{ml}$ culture vessel and treated with $0,3.0$ and $12.0 \mathrm{mM} \mathrm{CSP}$ at $37^{\circ} \mathrm{C}$. When cells reached a final concentration of $1 \times 10^{5}$ cells $/ \mathrm{ml}$, they were subsequently cultured at $37^{\circ} \mathrm{C}$ in a $5 \% \mathrm{CO}_{2}$ incubator for $24 \mathrm{~h}$. The harvested cells were fixed with $2.5 \%$ glutaraldehyde for $24 \mathrm{~h}$ and $1.5 \%$ osmium acid for $2 \mathrm{~h}$ at room temperature, dried and coated with gold by an ion sputtering coating machine. Finally, the cells were observed using a scanning electron microscope (Hitachi H-7650; Hitachi, Ltd., Tokyo, Japan).

Cell apoptosis analysis. Cell apoptosis rates were determined using an Annexin V fluorescein isothiocyanate(FITC)/propidium iodide (PI) staining assay and flow cytometry (BD Biosciences, Franklin Lakes, NJ, USA). Briefly, DU-145 cells were cultured in 6-well flat-bottomed plates at $37^{\circ} \mathrm{C}$ for $24 \mathrm{~h}$ and then treated with $0,3.0,12.0$ and $18.0 \mathrm{mM}$ CSP for a further $24 \mathrm{~h}$. Harvested cells were then digested with $0.25 \%$ trypsin, resuspended in phosphate buffer and then collected by centrifugation $(1,000 \mathrm{x} \mathrm{g}$, $4^{\circ} \mathrm{C}$ for $\left.5 \mathrm{~min}\right)$. Finally, the cells were incubated with $5 \mu \mathrm{l}$ of Annexin V-FITC and $10 \mu \mathrm{l}$ of PI for $15 \mathrm{~min}$ at room temperature in the dark and then immediately analyzed by flow cytometry using a flow cytometer.

Western blot analysis. Total protein lysates from the different cell groups were extracted using RIPA lysis buffer (Beyotime Institute of Biotechnology, Shanghai, China), quantified by using BCA protein assay kit and equal amounts of protein $(50 \mu \mathrm{g})$ were loaded per well on a $10 \%$ SDS-PAGE gel and then separated. Following SDS-PAGE, proteins were transferred to a polyvinylidene difluoride membrane and the membrane was then blocked using $10 \%$ non-fat milk for $1.5 \mathrm{~h}$ at room temperature. The membrane was incubated with specific primary antibodies ( $\beta$-actin, Bax, Bcl-2, caspase-3 and caspase-9; $1: 1,000)$ at $4{ }^{\circ} \mathrm{C}$ overnight and then washed three times using Tris- $\mathrm{HCl}$ with $0.05 \%$ Tween-20. Following this, the membrane was incubated with horseradish peroxidase-conjugated goat-anti-rabbit secondary antibodies $(1: 3,000)$ at room temperature for $2 \mathrm{~h}$. The intensity of specific bands was visualized using enhanced chemiluminescence (FluorChem FC3, Protein Simple, Inc., San Jose, CA, USA) and then quantified using Quantity One software (version 4.62; Bio-Rad Laboratories, Inc., Hercules, CA, USA).

Statistical analysis. Data are presented as the mean \pm standard deviation of at least four independent experiments. Data were analyzed by one-way analysis of variance with Turkey's test using the SPSS 19.0 software (IBM Corps., Armonk, NY, USA). $\mathrm{P}<0.05$ was considered to indicate a significant difference.

\section{Results and Discussion}

Purification of activity peptide and peptide identification. The target peptide was purified from Cyclina sinensis protein hydrolysates via ultrafiltration, gel filtration chromatography and RP-HPLC. The anti-proliferative activity of the peptide against DU-145 cells was used to monitor the purification process. The $<3 \mathrm{kDa}$ peptide fraction was revealed to demonstrate the greatest anti-proliferative activity towards DU-145 cells $(89.46 \pm 4.47 \%$; Fig. 1A). Chi et al (9) reported that $<1 \mathrm{kDa}$ peptide fractions isolated from blood clam protein hydrolysates exhibit the greatest anti-proliferative activity against 


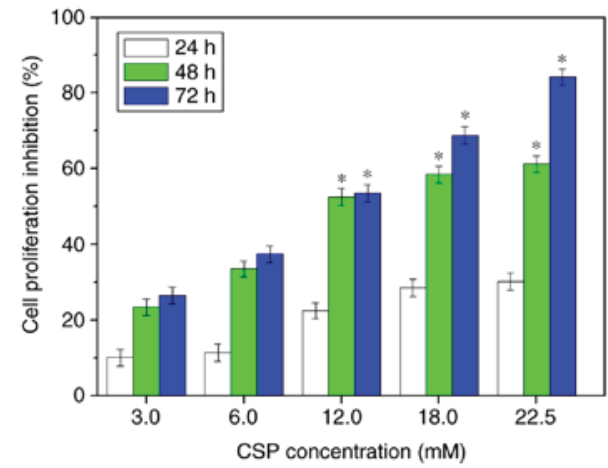

Figure 2. Inhibition of DU-145 cell proliferation treated with numerous concentrations of CSP. DU-145 cells were treated with numerous concentrations of $\operatorname{CSP}(0,3.0,6.0,12.0,18.0$ and $22.5 \mathrm{mM})$ for 24,48 and $72 \mathrm{~h}$ time intervals at $37^{\circ} \mathrm{C}$, and the inhibition of cell proliferation was investigated using a MTT assay. The half-maximal inhibitory concentration of CSP was $\sim 11.25 \mathrm{mM}$ at $72 \mathrm{~h}$. The results were normalized to the $0 \mathrm{mM}$ CSP group. $\mathrm{P}<0.05$ vs. $24 \mathrm{~h}$.

PC-3, DU-145 and H1299 cells. Similar results were observed in protein hydrolysates obtained from Setipinna taty and Ruditapes philippinarum $(26,27)$. The results of the present study were consistent with previous findings suggesting that short peptides exhibited greater anticancerous activities, and thus $<3 \mathrm{kDa}$ peptide fractions were subsequently collected and lyophilized for further investigation.

Following this, fractions $<3 \mathrm{kDa}$ were separated into three sub-fractions (peak 1, peak 2 and peak 3 ). The results of the MTT assay revealed that peak 3 exhibited the greatest anti-proliferative activity $(12 \mathrm{mM} ; 59.46 \pm 3.67 \%$ CSP treatment for $24 \mathrm{~h}$ ) towards DU-145 cells compared with peak 1 and peak 2 (Fig. 1B). Subsequently, peak 3 was collected, lyophilized and further purified via preparative RP-HPLC. The peak with a retention time of $6.480 \mathrm{~min}$ demonstrated the greatest inhibitory effect on DU-145 cell proliferation (Fig. 1C). Following this, this peak was further purified 20 times via preparative RP-HPLC and subsequently subjected to MS and amino acid sequence analysis. Following analysis using a Shimadzu PPSQ-31A protein sequencer and electrospray ionization-mass spectrometry, the amino acid sequence of CSP was determined to be ILYMP (Fig. 1C) with a molecular weight of $635.35 \mathrm{Da}\left[(\mathrm{M}+\mathrm{H})^{+}\right.$; Fig 1D], which was consistent with a theoretical mass of CSP (635.71 Da).

CSP exhibits an anti-proliferative effect against DU-145 cells. Cell proliferation occurs in almost all tissues and regulates cell proliferation and programmed cell death in order to ensure tissue and organ integrity. However, uncontrolled cell division may result in tissue hyperplasia as well as the development of diseases, such as cancer $(10,28)$. Thus, inhibition of cell proliferation is considered to represent an effective therapeutic strategy for the treatment of cancer. In the present study, MTT assays were used to determine the inhibitory effect of CSP on DU-145 cell proliferation. The results revealed that CSP exhibited a marked increase in cytotoxicity against DU-145 cells in a dose-dependent manner, with an inhibition rate of $\sim 84.17 \%$ at $22.5 \mathrm{mM}$ at the $72 \mathrm{~h}$ time interval (Fig. 2). The half-maximal inhibitory concentration $\left(\mathrm{IC}_{50}\right)$ of CSP was $\sim 11.25 \mathrm{mM}$ at the $72 \mathrm{~h}$ time interval. Furthermore, CSP did not exhibit any toxicity
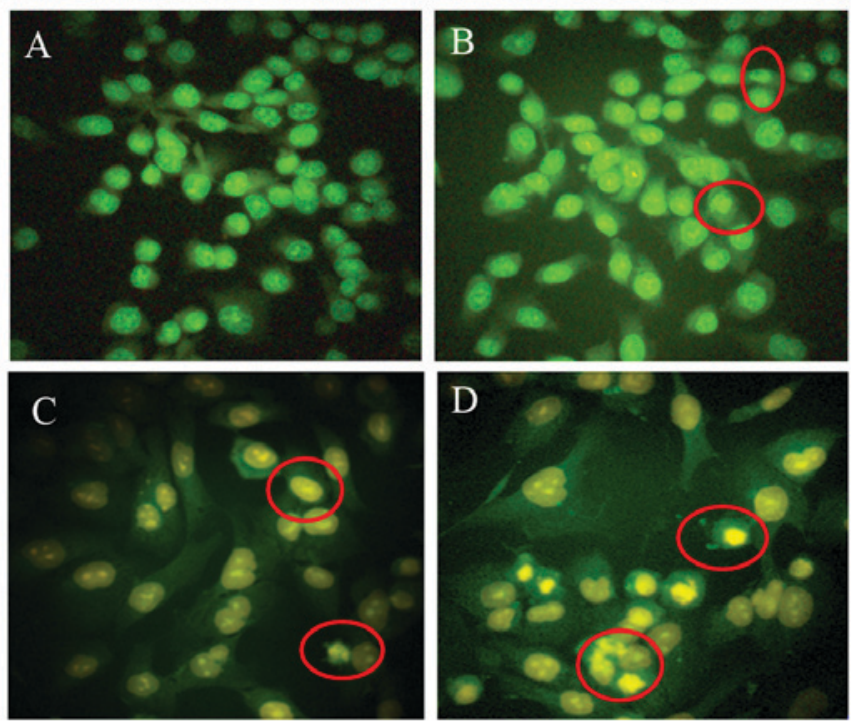

Figure 3. Morphological observation via acridine orange/ethidium bromidestaining (magnification, $x 400$ ). (A) Cells were treated with (A) 0 , (B) 3.0 (C) 12.0 and (D) $18.0 \mathrm{mM}$ CSP. Red circles represent (B) viable cells, (C) early apoptotic cells (D) and late apoptotic cells. Each experiment was performed in triplicate $(n=3)$ and generated similar morphologic features.

towards the normal NIH-3T3 cells (data not shown), which are frequently used as a healthy control cell line (8). Therefore, the results suggested that CSP exhibited selective toxicity towards cancer cells compared with normal cells.

Morphological observations. AO/EB staining has been previously used to investigate apoptosis in cancer cells $(25,29)$. The present study aimed to determine whether CSP-induced inhibition of cell proliferation occurs via apoptosis by treating DU-145 cells with 3.0, 12.0 and 18.0 mM CSP and observing changes in cell morphology using AO/EB staining (Fig. 3). Early-stage apoptotic cells, marked by crescent-shaped or granular yellow green AO nuclear staining, were observed following treatment with 3.0 and $12.0 \mathrm{mM} \mathrm{CSP}$ for $24 \mathrm{~h}$, which suggested that DU-145 cells were undergoing early stage apoptosis (Fig. 3A, B and C). Late-stage apoptotic cells, with concentrated and asymmetrically localized nuclear $\mathrm{AO} / \mathrm{EB}$ staining, were observed following treatment with $18.0 \mathrm{mM}$ CSP for $24 \mathrm{~h}$ (Fig. 3D). The morphological characteristics of apoptotic DU-145 cells in the present study were similar to the results of $\mathrm{AO} / \mathrm{EB}$ staining in previous studies using DU-145, PC-3 and LNCaP cells that were treated with sepia ink oligopeptide QPK (18), HeLa cells treated with a hexapeptide (Phe-Ile-Met-Gly-Pro-Tyr; FIMGPY) isolated from Raja porosa cartilage protein hydrolysates (10) and PC-3 cells treated with a peptide (Arg-Asp-Gly-Asp-Ser-Cys-ArgGly-Gly-Gly-Pro-Val; RDGDSCRGGGPV) isolated from Bullacta exarata (30).

Scanning electron microscopy was used to further investigate the effects of CSP on DU-145 cells. Cells in the control group did not exhibit any typical morphological changes (microvilli reduction or disappearance, chromatin condensation or margination) (Fig. 4A and B). However, typical morphological changes were observed when cells were treated with 3.0 (Fig. 4C and D) and $12.0 \mathrm{mM}$ CSP for 

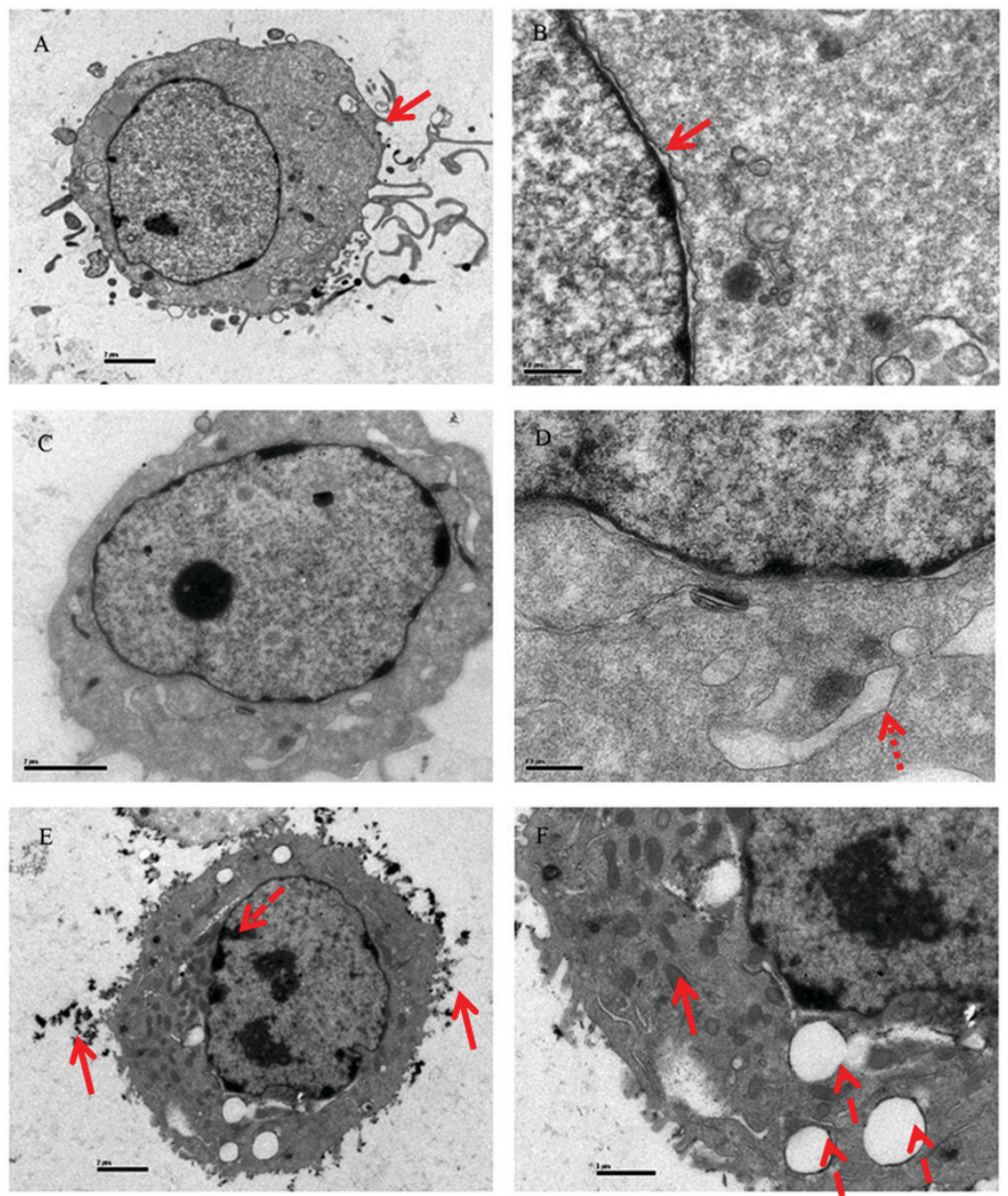

Figure 4. Morphological observation of DU-145 cells revealed by scanning electron microscopy. Untreated cells did not exhibit any typical morphological changes at (A) magnification, x3,700, the red arrow with the solid line in (A) indicates abundant microvilli are observed on the surface and (B) magnification, $x 17,500$, the red arrow with the solid line in (B) indicates nuclear membrane was intact. Cells treated with 3.0 mM CSP at (C) magnification, x6,200 and (D) magnification, $\mathrm{x} 17,500$, the red arrow with the small dots in (D) indicates a smooth endoplasmic reticulum extension. Cells treated with 12.0 mM CSP at (E) magnification, $x 3,700$ and (F) magnification, $x 8,900$. The red arrow with the solid line in (E) indicates heterochromatin aggregation and the red arrow with long dashes indicates microvilli loss. The red arrow with the long dash in (F) indicates vacuoles appearing in the cytoplasm and the red arrow with the solid line indicates mitochondrial ridges disappearing.

$24 \mathrm{~h}$ (Fig. 4E and F), such as a loss of microvilli structures on the surface of the cell membrane, chromatin condensation and the presence of apoptosis bodies. Furthermore, an expansion of the smooth endoplasmic reticulum, loss of mitochondrial cristae and an appearance of numerous cytoplasmic vacuoles were observed in CSP-treated DU-145 cells. In conclusion, these results suggested that apoptosis is enhanced in cells following treatment with CSP, and the morphological features observed were similar to those observed in DU-145 cells following treatment with an oligopeptide (Asp-Trp-Pro, DWP) isolated from Ruditapes philippinarum (31).

Cell apoptotic rate is enhanced in DU-145 cells following treatment with CSP. Cancer is a disease state characterized by disordered cell proliferation and inhibition of apoptosis. Previous therapeutic strategies for the treatment of tumors have focused on the inhibition of cell proliferation and the induction of apoptosis. In order to further investigate the induction of apoptosis by CSP, flow cytometric analysis was performed and the rate of cellular apoptosis was determined using Annexin V-FITC/PI double staining. The results revealed that the percentage of Annexin V-FITC stained DU-145 cells in the control group was $6.10 \pm 1.1 \%$ (Fig. 5A). Following $24 \mathrm{~h}$ exposure to $3.0,12.0$, and $18.0 \mathrm{mM} \mathrm{CSP}$, the percentage of apoptotic cells increased to $9.01 \pm 1.3 \%$ (Fig. 5B), 12.36 $\pm 1.8 \%$ (Fig. 5C) and $20.18 \pm 1.9 \%$ (Fig. 5D), respectively; thus demonstrating a marked increase in apoptosis rates following treatment with CSP in a dose-dependent manner. Therefore, the results suggested that CSP induced apoptosis in DU-145 cells.

\section{Expression levels of apoptosis associated proteins in DU-145} cells are increased following treatment with CSP. The results of the flow cytometry analysis suggested that apoptosis was increased in DU-145 cells following treatment with CSP in a dose-dependent manner. In order to investigate the underlying mechanisms, expression levels of anti- and pro-apoptosis associated proteins were determined in CSP-treated DU-145 cells via western blotting. The Bcl-2 protein family plays an important role in the regulation of apoptosis, and includes pro-apoptotic proteins (Bax, Bcl-2 associated agonist of cell death and $\mathrm{Bcl}-\mathrm{X})$ as well as anti-apoptotic proteins (Bcl-2, Bcl-extra large and Bcl-2-like protein) (32). Thus, the ratio 

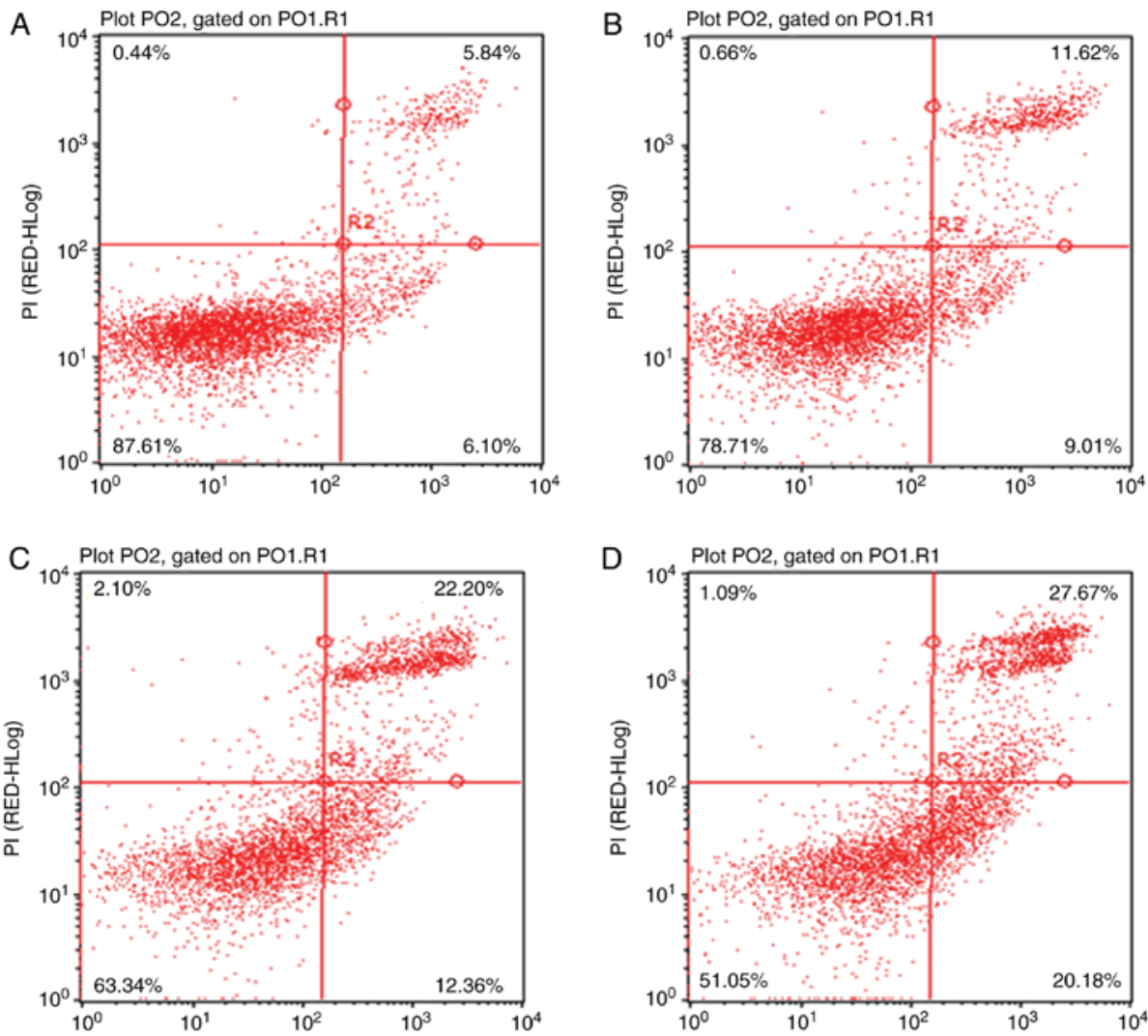

Figure 5. Flow cytometry analysis of DU-145 cells following Annexin V-FITC and PI double staining. The percentage of early apoptotic cells was (A) 6.10\% in untreated cells, (B) $9.01 \%$ in 3.0 mM CSP-treated cells, (C) $12.36 \%$ in 12.0 mM CSP-treated cells and (D) $20.18 \%$ in 18.0 mM CSP-treated cells. Quadrants: Lower left, live cells; upper left, necrotic cells; lower right, early apoptotic cells; upper right, late apoptotic cells. Each experiment was performed in triplicate $(\mathrm{n}=3)$ and generated similar morphologic features. PI, propidium iodide.
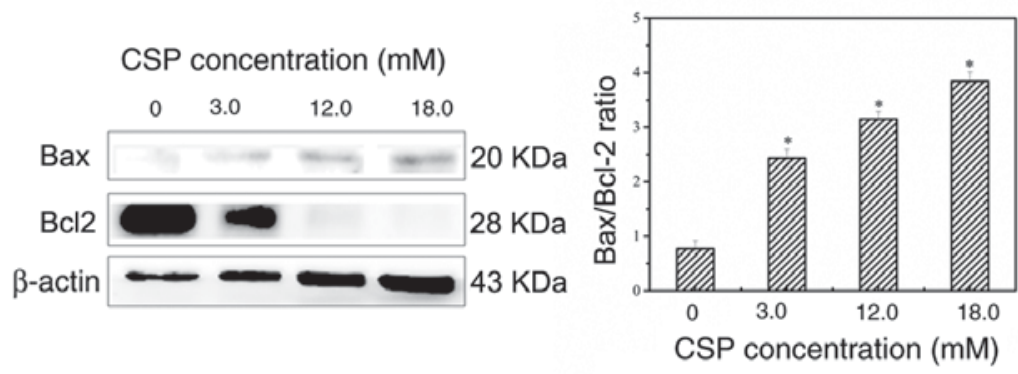

Figure 6. Expression of Bax and Bcl-2 apoptosis-associated proteins in DU-145 cells treated with CSP for $24 \mathrm{~h}$. DU-145 cells were treated with different concentrations of CSP $(0.0,3.0,12.0$ and $18.0 \mathrm{mM})$ for $24 \mathrm{~h}$ at $37^{\circ} \mathrm{C}$ and the protein expression levels of Bax and Bcl-2 were determined via western blotting. Bcl-2 expression was significantly decreased and the expression of Bax was significantly increased following treatment with CSP in a dose-dependent manner. CSP, Cyclina sinensis; Bcl-2, B-cell lymphoma 2; Bax, Bcl-2-associated X. P<0.05 vs. 0 mM CSP.

between Bax and Bcl-2 protein expression is frequently used as an apoptotic index $(10,18,25)$. The western blotting results demonstrated that $\mathrm{Bcl}-2$ expression was significantly decreased, whereas the expression of Bax was significantly increased following treatment with CSP in a dose-dependent manner, thus resulting in a dose-dependent increase in the $\mathrm{Bax} / \mathrm{Bcl}-2$ ratio in CSP-treated DU-145 cells (Fig. 6). These results therefore suggested that treatment with CSP significantly enhanced apoptosis via upregulation of the $\mathrm{Bax} / \mathrm{Bcl}-2$ ratio in DU-145 cells.

In addition, caspase proteins are important for the maintenance of cellular homeostasis via the regulation of cell death and inflammation, and may be classified as initiator caspases (caspase-8/9) or executioner caspases (caspase-3/6/7) (33). Caspase-9 protein is an important component of the mitochondrial death pathway and caspase- 3 is the predominant downstream effector caspase responsible for cleaving the majority of the cellular substrates in apoptotic cells (34). Western blotting analysis revealed that the protein expression of cleavedcaspase-3 and cleavedcaspase- 9 were significantly increased following treatment with CSP in a dose-dependent manner (Fig. 7). Therefore, the results suggest that CSP-induced apoptosis is associated with the mitochondrial-mediated death pathway in DU-145 cells. 

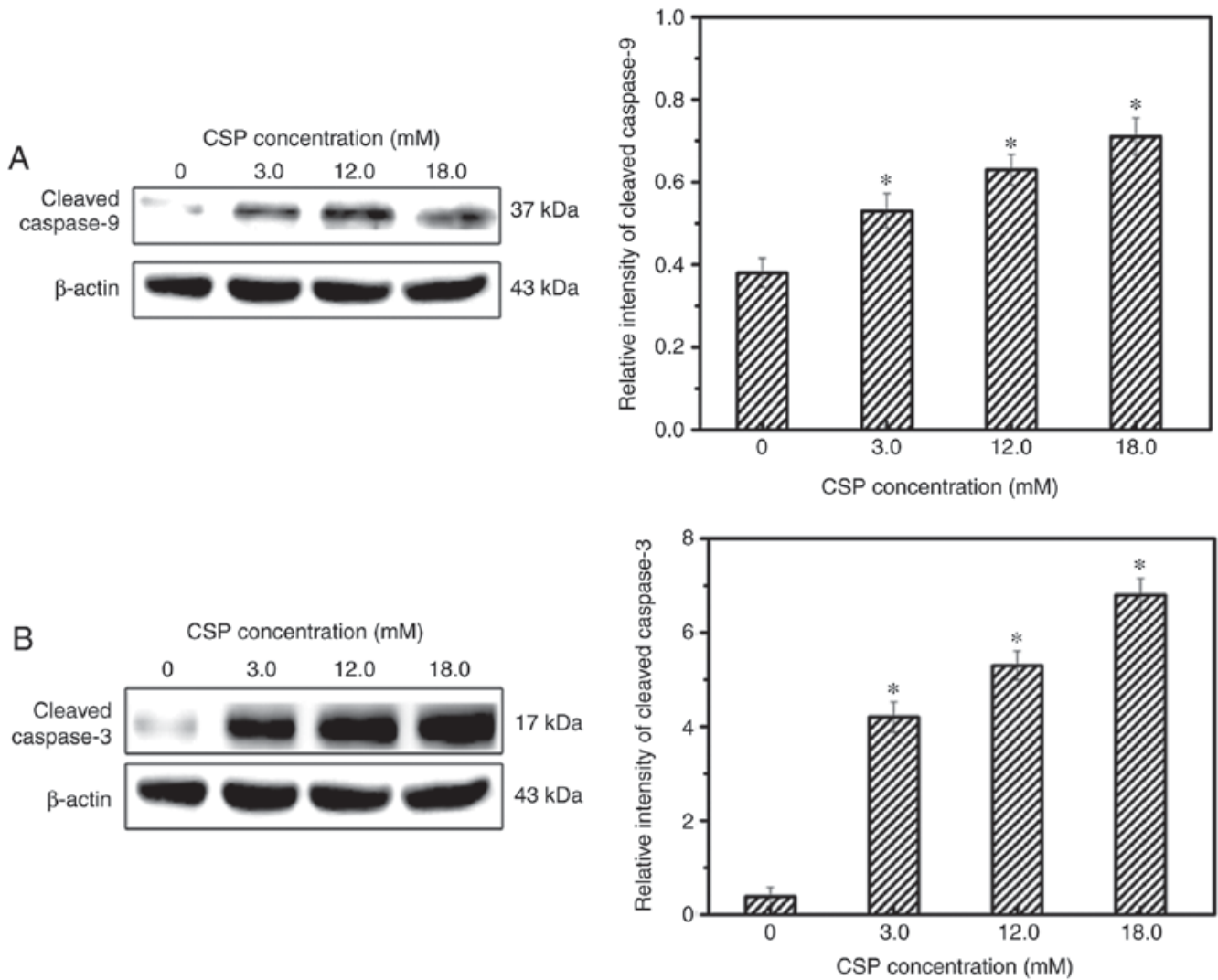

Figure 7. Expression of cleaved caspase- 9 and cleaved caspase-3 apoptosis-associated proteins in DU-145 cells treated with CSP for 24 h. DU-145 cells were treated with numerous concentrations of $\operatorname{CSP}(0,3.0,12.0$ and $18.0 \mathrm{mM})$ for $24 \mathrm{~h}$ at $37^{\circ} \mathrm{C}$, and the protein expression levels of (A) cleaved caspase-9 and (B) cleaved caspase-3 were determined via western blotting analyses. The protein expression levels of cleaved caspase-3 and cleaved caspase-9 were revealed to be significantly enhanced following treatment with CSP in a dose-dependent manner. The expression of all groups was normalized to $\beta$-actin. P $<0.05 \mathrm{vs.} 0 \mathrm{mM}$ CSP.

CSP exhibits anticancer activity. It has been previously established that the hydrophobic properties of amino acids affect their anticancer activities. For example, the A and L residues in the YALPAH peptide isolated from Setipinna taty peptide hydrolysates were revealed to be associated with its anti-proliferative activities against PC-3 cells (26). F, I, M, P and $\mathrm{Y}$ residues in the sequence of the FIMGPY hexapeptide isolated from Raja porosa cartilage were also demonstrated to be associated with its anticancer activities against HeLa cells (10). Therefore, it can be suggested that the amino acid residues in the CSP sequence (ILYMP) may contribute to its anticancer activities. The CSP isolated from Cyclina sinensis exhibited anticancer activity to DU-145 cells, with lower toxicity to normal cells. The properties of this pentapeptide make it a promising therapeutic agent for PCa prevention or treatment. Further investigation in future studies is required to fully characterize CSP activity both in vitro and in vivo.

In conclusion, an anti-proliferation pentapeptide (ILYMP) named CSP was obtained from protein hydrolysates isolated from Cyclina sinensis via ultrafiltration and chromatographic methods. The results revealed that CSP inhibited the proliferation of DU-145 cells with an $\mathrm{IC}_{50}$ of $11.25 \mathrm{mM}$ at $72 \mathrm{~h}$. Furthermore, AO/EB staining, scanning electron microscopy and flow cytometry analyses demonstrated that CSP suppresses DU-145 cell proliferation via the induction of apoptosis. Enhanced expression of Bax and cleaved caspase-3/9 as well as suppression of Bcl-2 expression was observed in CSP-treated DU-145 cells. To the best of the authors' knowledge, this is the first study to investigate the effects of an antiproliferative peptide on DU-145 cells derived from Cyclina sinensis, and the results revealed that the Cyclina sinensis extract may have a therapeutic effect on PCa. However, the underlying mechanism of CSP-induced apoptosis was not fully determined, and our future studies will focus on revealing the molecular and proteomic mechanisms associated with this effect, using in vitro and in vivo studies.

\section{Acknowledgements}

The authors would like to thank Dr. Xiaojun Zhang from Aquatic Processing Department, Zhejiang Marine Fisheries Research Institution for measuring the molecular weight of the CSP.

\section{Funding}

This research was supported by the Natural Science Foundation of Zhejiang Province (grant nos. LQ16H300001, LY12C20005 and LY12C20008), the Foundation of Zhejiang Educational Committee (grant no. Y201534400) and the Public Welfare Program of Zhoushan (grant no. 2015C31012).

\section{Availability of data and materials}

The data used in the current study are available from the corresponding author on reasonable request. 


\section{Authors' contributions}

ZY and FY conceived and designed the experiments. YZ, LY and YT performed the experiments. GD and XZ conducted data analysis. All authors read and approved the manuscript.

\section{Ethics approval and consent to participate}

Not applicable.

\section{Consent for publication}

Not applicable.

\section{Competing interests}

The authors declare that they have no competing interests.

\section{References}

1. Torre LA, Bray F, Siegel RL, Ferlay J, Lortet-Tieulent J and Jemal A: Global cancer statistics, 2012. CA Cancer J Clin 65: 87-108, 2015

2. Choo GS, Lee HN, Shin SA, Kim HJ and Jung JY: Anticancer effect of fucoidan on DU-145 prostate cancer cells through inhibition of PI3K/Akt and MAPK pathway expression. Mar Drugs 14: E126, 2016.

3. Zhou Y, Ji Z, Yan W, Zhou Z and Li H: The biological functions and mechanism of miR-212 in prostate cancer proliferation, migration and invasion via targeting Engrailed-2. Oncol Rep 38: 1411-1419, 2017.

4. Hu MB, Bai PD, Wu YS, Zhang LM, Xu H, Na R, Jiang HW and Ding Q: Higher body mass index increases the risk for biopsy-mediated detection of prostate cancer in Chinese men. PloS One 10: e0124668, 2015.

5. Guo L, Min Y, Zhong J, Wu H, Pan J, Gong W, Wang M, Fei F and Hu R: Stroke risk among patients with Type 2 diabetes mellitus in Zhejiang: A population-based prospective study in China. Int J Endocrinol 2016: 6380620, 2016.

6. Karantanos T, Corn PG and Thompson TC: Prostate cancer progression after androgen deprivation therapy: Mechanisms of castrate resistance and novel therapeutic approaches. Oncogene 32: 5501-5511, 2013.

7. Fizazi K, Scher HI, Molina A, Logothetis CJ, Chi KN, Jones RJ, Staffurth JN, North S, Vogelzang NJ, Saad F, et al: Abiraterone acetate for treatment of metastatic castration-resistant prostate cancer: Final overall survival analysis of the COU-AA-301 randomised, double-blind, placebo-controlled phase 3 study. Lancet Oncol 13: 983-992, 2012.

8. Schrader AJ, Boegemann M, Ohlmann CH, Schnoeller TJ, Krabbe LM, Hajili T, Jentzmik F, Stoeckle M, Schrader M, Herrmann E and Cronauer MV: Enzalutamide in castration-resistant prostate cancer patients progressing after docetaxel and abiraterone. Eur Urol 65: 30-36, 2014.

9. Chi CF, Hu FY, Wang B, Li T and Ding GF: Antioxidant and anticancer peptides from the protein hydrolysate of blood clam (Tegillarca granosa) muscle. J Funct Foods 15: 301-313, 2015.

10. Pan X, Zhao YQ, Hu FY, Chi CF and Wang B: Anticancer activity of a hexapeptide from Skate (Raja porosa) cartilage protein hydrolysate in HeLa Cells. Mar Drugs 14: E153, 2016.

11. Zhang Z, Gao L, Shen C, Rong M, Yan X and Lai R: A potent anti-thrombosis peptide (vasotab TY) from horsefly salivary glands. Int J Biochem Cell Biol 54: 83-88, 2014.

12. Wang B, Wang YM, Chi CF, Luo HY, Deng SG and Ma JY: Isolation and characterization of collagen and antioxidant collagen peptides from scales of Croceine Croaker (Pseudosciaena crocea). Mar Drugs 11: 4641-4661, 2013.

13. Pan X, Zhao YQ, Hu FY and Wang B: Preparation and identification of antioxidant peptides from protein hydrolysate of skate (Raja porosa) cartilage. J Funct Foods 25: 220-230, 2016.

14. Wang X, Xing R, Chen Z, Yu H, Li R and Li P: Effect and mechanism of mackerel (Pneumatophorus japonicus) peptides for anti-fatigue. Food Funct 5: 2113-2119, 2014.
15. Zhao YQ, Zeng L, Yang ZS, Huang FF, Ding GF and Wang B: Anti-fatigue effect by peptide fraction from protein hydrolysate of Croceine Croaker (Pseudosciaena crocea) swim bladder through inhibiting the oxidative reactions including DNA damage. Mar Drugs 14: 221, 2016.

16. Ovchinnikova TV, Aleshina GM, Balandin SV, Krasnosdembskaya AD, Markelov ML, Frolova EI, Leonova YF, Tagaev AA, Krasnodembsky EG and Kokryakov VN: Purification and primary structure of two isoforms of arenicin, a novel antimicrobial peptide from marine polychaeta Arenicola marina. FEBS Lett 577: 209-214, 2004.

17. Sperstad SV, Haug T, Blencke HM, Styrvold OB, Li C and Stensvåg K: Antimicrobial peptides from marine invertebrates: Challenges and perspectives in marine antimicrobial peptide discovery. Biotechnol Adv 29: 519-530, 2011.

18. Huang F, Yang ZS, Yu D, Wang J, Li R and Ding G: Sepia ink oligopeptide induces apoptosis in prostate cancer cell lines via caspase-3 activation and elevation of Bax/Bcl-2 ratio. Mar Drugs 10: 2153-2165, 2012.

19. Song R, Wei R, Zhang B, Yang Z and Wang D: Antioxidant and antiproliferative activities of heated sterilized pepsin hydrolysate derived from half-fin anchovy (Setipinna taty). Mar Drugs 9: $1142-1156,2011$

20. Kim EK, Hwang JW, Kim YS, Ahn CB, Jeon YJ, Kweon HJ, Bahk YY, Moon SH, Jeon BT and Park PJ: A novel bioactive peptide derived from enzymatic hydrolysis of Ruditapes philippinarum: Purification and investigation of its free-radical quenching potential. Process Biochem 48: 325-330, 2013.

21. Jiang C, Xiong Q, Gan D, Jiao Y, Liu J, Ma L and Zeng X: Antioxidant activity and potential hepatoprotective effect of polysaccharides from Cyclina sinensis. Carbohyd Polym 91: 262-268, 2013.

22. Jiang C, Xiong Q, Li S, Zhao X and Zeng X: Structural characterization, sulfation and antitumor activity of a polysaccharide fraction from Cyclina sinensis. Carbohyd Polym 115: 200-206, 2015.

23. Jiang C, Wang M, Liu J, Gan D and Zeng X: Extraction, preliminary characterization, antioxidant and anticancer activities in vitro of polysaccharides from Cyclina sinensis. Carbohyd Polym 84: 851-857, 2011.

24. Yan HQ, Teng FF, Liu ZX, Huang FF, Yang ZS and Ding GF: Anticancer activity of peptides isolated from hydrolysates of Cylcina sinensis. J Anhui Agri Sci 42: 3576-3577, 2014.

25. Tang Y, Yu F, Zhang G, Yang Z, Huang F and Ding G: A purified serine protease from Nereis virens and its impaction of apoptosis on human lung cancer cells. Molecules 22: E1123, 2017.

26. Song R, Wei RB, Luo HY and Yang ZS: Isolation and identification of an antiproliferative peptide derived from heated products of peptic hydrolysates of half-fin anchovy (Setipinna taty). J Funct Foods 10: 104-111, 2014.

27. Kim EK, Kim YS, Hwang JW, Lee JS, Moon SH, Jeon BT and Park PJ: Purification and characterization of a novel anticancer peptide derived from Ruditapes philippinarum. Process Biochem 48: 1086-1090, 2013.

28. Ibrahim B, Sowemimo A, Spies L, Koekomoer T, Venter MVD and Odukoya OA: Antiproliferative and apoptosis inducing activity of Markhamia tomentosa leaf extract on HeLa cells. J Ethnopharmacol 149: 745-749, 2013.

29. Deng X, Qiu Q, Yang B, Wang X, Huang W and Qian H: Design, synthesis and biological evaluation of novel peptides with anti-cancer and drug resistance-reversing activities. Eur J Med Chem 89: 540-548, 2015.

30. Ma J, Huang F, Lin $\mathrm{H}$ and Wang X: Isolation and purification of a peptide from Bullacta exarata and its impaction of apoptosis on prostate cancer cell. Mar Drugs 11: 266-273, 2013.

31. Yang Z, Zhao Y, Yan H, Xu L, Ding G, Yu D and Sun Y: Isolation and purification of oligopeptides from Ruditapes philippinarum and its inhibition on the growth of DU-145 cells in vitro. Mol Med Rep 11: 1063-1068, 2015.

32. Kuwana T and Newmeyer DD: Bcl-2-family proteins and the role of mitochondria in apoptosis. Curr Opin Cell Biol 15: 691-699, 2003.

33. Mcilwain DR, Berger T and Mak TW: Caspase functions in cell death and disease. Cold Spring Harb Perspect Biol 5: a008656, 2013.

34. Kumar S: Caspase function in programmed cell death. Cell Death Differ 14: 32-43, 2007.

This work is licensed under a Creative Commons Attribution-NonCommercial-NoDerivatives 4.0 International (CC BY-NC-ND 4.0) License. 